\title{
Hemispherectomy: historical review and recent technical advances
}

\author{
Alexandra D. Beier, D.O., ${ }^{1}$ And James T. Rutka, M.D., Ph.D., F.R.C.S.C. ${ }^{2}$ \\ ${ }^{1}$ Division of Pediatric Neurological Surgery, University of Florida Health Science Center Jacksonville, \\ Florida; and ${ }^{2}$ Division of Neurosurgery, The Hospital for Sick Children and Department of Surgery, \\ University of Toronto, Ontario, Canada
}

\begin{abstract}
The surgical options available for intractable hemispheric epilepsy have evolved since their initial description in the early 20th century. Surgical techniques have advanced, as has the ability to predict good surgical outcomes with noninvasive diagnostics. The authors review the history of hemispherectomy and detail the novel imaging and surgical strategies used to confer seizure freedom. (http://thejns.org/doi/abs/10.3171/2013.3.FOCUS1341)
\end{abstract}

\author{
KeY WORDS • hemispherectomy • peri-insular hemispherotomy \\ epilepsy surgery
}

$\mathrm{T}$ HE treatment for intractable epilepsy has been evolving since Horsley performed the first surgery for epilepsy in $1886 . .^{13}$ For catastrophic epilepsy, the entire removal of one hemisphere was advocated in 1938 by McKenzie. ${ }^{2}$ Since then, several advances have brought the initially abandoned procedure back into favor for intractable hemispheric epilepsy. This article will highlight the recent developments and technical details of hemispherectomy.

\section{Historical Overview}

Initially, hemispherectomy was described and performed for tumor control. Both Dandy and Gardner reported series-in 1928 and 1933, respectively-on the treatment of malignant glioma. Due to significant mortality, the procedure was abandoned..$^{5,11}$ McKenzie revitalized the technique and applied it to epilepsy in 1938. Krynauw, reporting on 8 cases in his 1950 publication, was among the first to popularize the technique routinely for epilepsy in $19500^{2,12,17}$ Yet after a report by Oppenheimer and Griffith in 1960 that described delayed mortalities due to superficial hemosiderosis, the technique of anatomical hemispherectomy fell out of favor. ${ }^{20}$ Accord-

Abbreviations used in this paper: DTI = diffusion tensor imaging; $\mathrm{EEG}=$ electroencephalography; $\mathrm{MEG}=$ magnetoencephalography. ingly, to avoid superficial hemosiderosis, other surgical techniques were developed.

Functional hemispherectomy was devised by Rasmussen in $1974 .{ }^{27} \mathrm{He}$ is credited with developing the notion that hemispherectomy could be achieved through disconnection of the main crossing fibers, rather than resection. This technique was further modified by Villemure and Schramm with a peri-insular approach, and Delalande with a parasagittal disconnection procedure. Both techniques are known as "hemispherotomy.", $, 2,7,8$ Overall seizure freedom with the newer procedures range from $74 \%$ to $85 \% .^{2,24}$

\section{Preoperative Planning}

In order for a patient to be a candidate for surgery, his or her seizures have to be proven intractable. Although the definition of intractability varies in the literature, it typically involves failure of 3 first-line antiepileptic medications. Other variables that can predict intractability are: early age at seizure onset, remote symptomatic etiology, infantile spasms, status epilepticus, poor response to short-term antiepileptic therapy, and failure of initial antiepileptic drug trial. ${ }^{23}$ Hemispherectomy should only be performed for the treatment of epilepsy when seizures are limited to one hemisphere and when multifocal hemispheric resections would not be efficacious. In general, 
Sturge-Weber syndrome, cortical dysplasia, hemimegalencephaly, Rasmussen syndrome, porencephalic cyst, and hemiconvulsion-hemiplegia-epilepsy syndrome are diffuse hemispheric disorders that result in progressive epilepsy, and patients with these conditions may benefit from hemispherectomy. ${ }^{2,3}$

Isolating the epileptogenic zone is paramount in the preoperative evaluation; however, there is no specific study or test that accomplishes this. Routine testing includes interictal and ictal scalp video-EEG, MRI, and frequently PET and functional MRI. Magnetoencephalography has been used with increasing frequency in preoperative and postoperative epilepsy surgery. The events are modeled according to the MEG spike source localization and frequency. In our experience, $20 \mathrm{MEG}$ spike sources localized within $1 \mathrm{~cm}$ or less correlated with seizure outcome upon removal of the MEG spike sources at surgery. ${ }^{14} \mathrm{We}$ have recently described the use of MEG in over 600 epilepsy patients, with more than 200 accounting for surgical cases. From this series, there were 13 patients who underwent MEG for diffuse hemispheric epilepsy, where the MEG correlated to the video-EEG in the majority of cases and unilateral MEG spike waves correlated to good postoperative outcomes. ${ }^{26}$ RamachandranNair et al..$^{22}$ described the use of MEG with normal or nonfocal MRI and found that correlation between EEG and MEG predicted good seizure outcome, whereas seizure freedom was least likely to occur when the results of the studies were conflicting. MEG clusters were described as 6 or more spike sources with less than $1 \mathrm{~cm}$ between adjacent sources, with scatters containing fewer than 6 spike sources irrespective of the distance between sources, or spike sources separated by $1 \mathrm{~cm}$ or less irrespective of the number of sources. The authors concluded that the presence of a MEG cluster confined to the resection area is required for seizure freedom. Moreover, they found that patients with bilateral MEG dipole clusters or patients that had only scattered dipoles demonstrated worse seizure outcome. Recently, DTI has also been beneficial in assisting in locating the epileptogenic zone. Widjaja et al. ${ }^{31}$ reported on the use of DTI to identify white matter changes in children who have negative results on MRI. The authors performed DTI image analysis "on a group of controls across individual patients" (26 age-matched healthy controls and 24 patients with epilepsy). They then created statistical maps (based on differences in fractional anisotropy, mean diffusivity, and 3 eigenvalues), which described the white matter changes in both MRI-visible focal cortical dysplasia and MRI-negative localizationrelated epilepsy. This is important, as outcomes with respect to seizure control are better in patients who have anatomical abnormalities than in those with truly normal findings on imaging. Diffusion tensor imaging can help identify these subtle changes that might assist with localizing the affected hemisphere. ${ }^{31}$ In addition, DTI can confirm completeness of hemispheric disconnection and identify persistent residual areas of connectivity that can hinder seizure outcome (Fig. 1).

With regard to when to intervene, the timing of surgery varies. However, it is reasonably well accepted now that the shorter the time between seizure onset and sur- gery, the higher the success rate. It is also believed that the earlier the seizures are controlled, the better chance there is for psychosocial and cognitive development. Moreover, the ability for the dominant hemisphere to obtain language declines after the 6th to 8th year, thus supporting the role for earlier surgery. ${ }^{2,3}$

\section{Techniques of Hemispherectomy}

As the goal for hemispheric epileptic disorders is removal of the offending agent, the neurosurgical techniques include complete anatomical resection, cortical resection, multiple lobectomies with minimal disconnection, and maximal disconnection with minimal brain resection. Anatomical hemispherectomy offers good seizure control, in the range of $80 \%-90 \%$, but it has the associated morbidity and mortality of superficial hemosiderosis..$^{10,21}$ To counter superficial hemosiderosis, modifications have ensued that lead to safer postoperative courses. Hemidecortication involves resecting the cortex down to the white matter. This procedure prevents the contamination of the ventricular system with blood products, a problem seen with the conventional anatomical procedure. With hemidecortication, there is inherent difficulty in obtaining complete cortical resection, specifically on the basal and mesial side of the lobes. Accordingly, the seizure freedom rates are lower than with other procedures-approximately $50 \%-80 \% .^{2,18,19}$ Hemidecortication remains a good technique, especially if the ventricular anatomy is unfavorable to a ventricular approach. Functional hemispherectomy involves a temporal lobectomy, resection of the central region, and disconnection of the residual frontal and parietooccipital lobes. This provides a seizure freedom rate of $75 \% .^{2,27}$ In 1992, Delalande introduced the term "hemispherotomy" to move away from maximal brain resection to maximal disconnection with minimal resection. Two different approaches were developed for hemispherotomy: vertical and lateral. Several modifications have also ensued: interhemispheric, transopercular, transsylvian keyhole, peri-insular, ultrasound guided, modified lateral. ${ }^{2,4,6,8,15,24,25,29,30}$

We generally prefer a modified peri-insular hemispherotomy approach. A craniotomy based on the insula is performed, and the dura is opened. Resecting the frontoparietal opercular cortex down to the insular pial bank creates the supra-insular window. The infra-insular window is created similarly by resecting the temporal opercular cortex (Fig. 2). The sylvian vessels are protected and preserved. An anterolateral temporal lobectomy including mesial structures is often performed and allows sufficient space in the event there is postoperative cerebral edema. The corona radiata is transected by opening the temporal horn posteriorly and continuing around to the frontal horn of the lateral ventricle. A callosotomy is performed by identifying the peri-callosal vessels just posterior to the foramen of Monro and following the vessels and the free edge of the falx cerebri posteriorly as it merges with the free edge of the tentorium cerebelli (Fig. 3 ). If a temporal lobectomy is not performed, the temporal lobe is disconnected by incising the fimbria fornix at the level of the splenium. The frontal disconnection is cre- 


\section{Hemispherectomy}
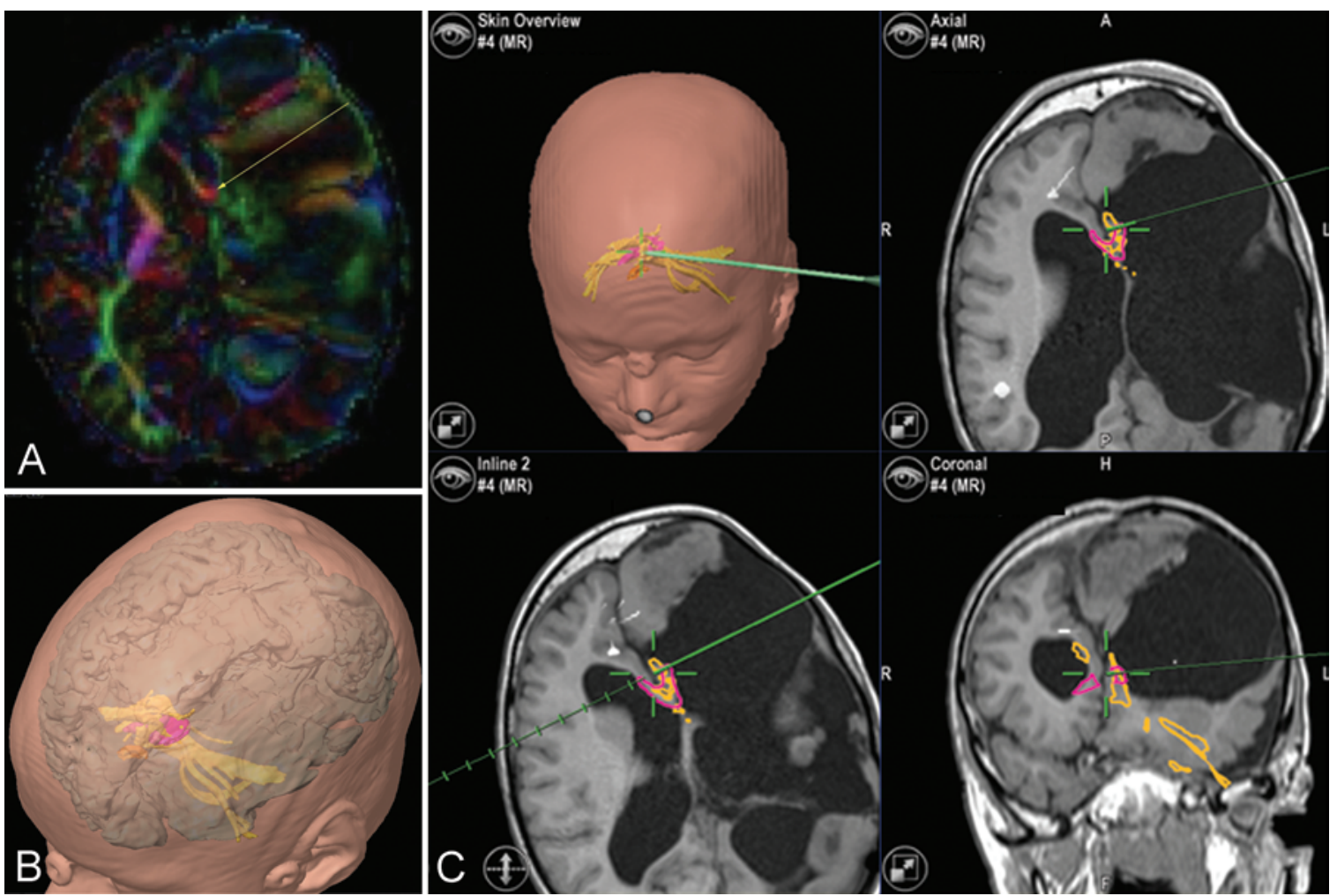

FIG. 1. Illustrative case. Images obtained in a 6-year-old child with left hemimegalencephaly who had undergone peri-insular hemispherotomy at the age of 1 year. After the initial surgery, he was free of seizures for 5 years, but then the seizures recurred. A DTI study revealed a small remaining tract. The residual tract was disconnected by means of neuronavigation-guided surgery, and the child regained seizure freedom. A: A DT image depicting residual connectivity at the genu of the corpus callosum. B: A 3D image outlining the residual tract connecting the 2 hemispheres. C: Intraoperative neuronavigation targeting the residual tract.

ated by transecting the frontal lobe in a subpial fashion to the medial interhemispheric pia. Lastly, the insular cortex is subpially resected, preserving the penetrating arteries.

\section{Outcome}

Overall, hemispherectomy bestows an excellent sei-

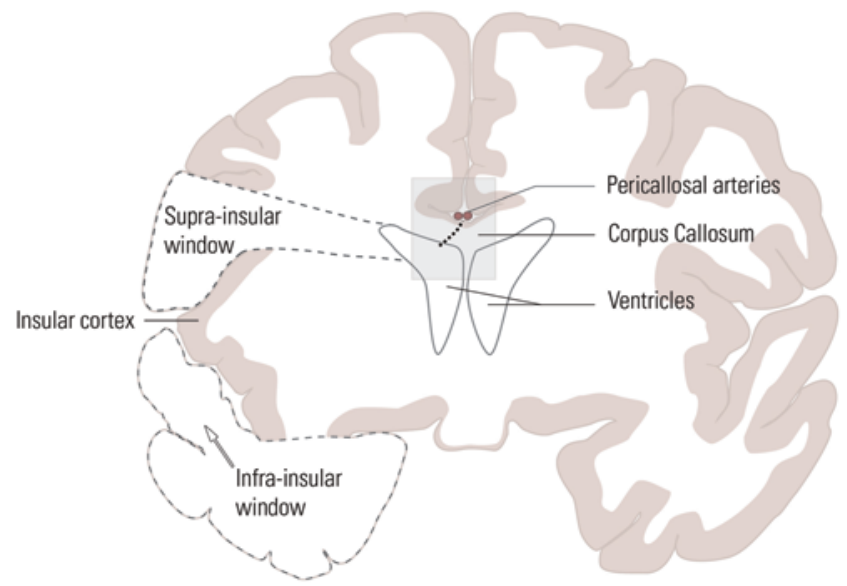

FIG. 2. Artist's rendition of supra- and infra-insular windows, with dotted line outlining the callostomy. From Beier A and Rutka J: Hemispherectomy. In Albright AL, et al.: Principles and Practice of Pediatric Neurosurgery, 3rd ed. New York: Thieme, expected 2013 (used with permission). zure control rate of $85 \%-100 \%$, with better outcomes seen in patients with Sturge-Weber syndrome, Rasmussen encephalitis, and focal infarct pathology. $8,16,18,21,25,26,28$ When we compared hemidecortication against peri-insu-

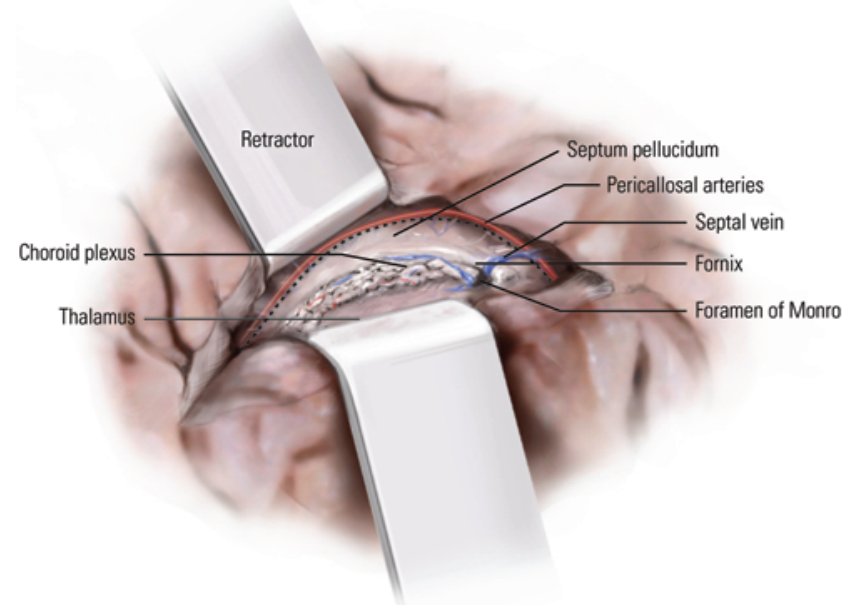

Fig. 3. Artist's rendition of intraventricular view prior to performing callostomy (dotted line), highlighting the foramen of Monro, peri-callosal arteries, and fornix. From Beier A and Rutka J: Hemispherectomy. In Albright AL, et al.: Principles and Practice of Pediatric Neurosurgery, 3rd ed. New York: Thieme, expected 2013 (used with permission). 
lar hemispherotomy at the Hospital for Sick Children, we demonstrated a seizure outcome advantage with hemispherotomy. ${ }^{18}$ The expected hemiparesis due to transection of the corticospinal tracts does not appear to affect ambulatory status in most series. ${ }^{16,18}$ In addition, performing a hemispherectomy appears to stop the progressive neurocognitive decline that can be seen with infantile epilepsy syndromes. ${ }^{9}$

Historically, the major cause of morbidity and mortality was superficial hemosiderosis. However, with the recent modifications and favoring of minimal brain resection and maximal disconnection, the current complications include postoperative infarcts, hydrocephalus, anemia from blood loss, and sinus thrombosis..$^{2,10}$

\section{Conclusions}

Significant advances have been made in surgery for intractable epilepsy over the last century. Defining the epileptogenic zone noninvasively with a myriad of new techniques will allow our ability to predict surgical candidacy to improve, as well as obtain seizure freedom in the majority of patients. Hemispherectomy, once associated with significant morbidity, has now also evolved into a safe, effective procedure for catastrophic epilepsy. The introduction of new neuroimaging techniques such as MEG and DTI has facilitated our abilities to enhance the workup and investigation of the child with a profound hemispheric epileptic disturbance. Swift workup and investigation will ensure that children who are candidates for hemispherectomy can be identified early and can go to surgery with the expectation of long-term excellent seizure control.

\section{Disclosure}

The authors report no conflict of interest concerning the materials or methods used in this study or the findings specified in this paper.

Author contributions to the study and manuscript preparation include the following. Conception and design: both authors. Acquisition of data: both authors. Analysis and interpretation of data: both authors. Drafting the article: both authors. Critically revising the article: both authors. Reviewed submitted version of manuscript: both authors. Approved the final version of the manuscript on behalf of both authors: Beier. Study supervision: both authors.

\section{References}

1. Binder DK, Schramm J: Multilobar resections and hemispherectomy, in Engel J Jr, Pedley TA (eds): Epilepsy: A Comprehensive Textbook, ed 2. Philadelphia: Wolters Kluwer Health/Lippincott Williams \& Wilkins, 2008, pp 1879-1890

2. Çataltepe O: Hemispherectomy and hemispherotomy techniques in pediatric epilepsy surgery: an overview, in Çataltepe O, Jallo GI (eds): Pediatric Epilepsy Surgery: Preoperative Assessment and Surgical Treatment. New York: Thieme, 2010, pp 205-214

3. Cline MJ, Ellenbogen RG: Epilepsy surgery is not useful for the Landau-Kleffner syndrome, in Miller JW, Silbergeld DL (eds): Epilepsy Surgery: Principles and Controversies. New York: Taylor \& Francis, 2005, pp 177-180

4. Cook SW, Nguyen ST, Hu B, Yudovin S, Shields WD, Vinters $\mathrm{HV}$, et al: Cerebral hemispherectomy in pediatric patients with epilepsy: comparison of three techniques by pathological substrate in 115 patients. J Neurosurg 100 (2 Suppl Pediatrics):125-141, 2004

5. Dandy WE: Removal of right cerebral hemisphere for certain tumors with hemiplegia. JAMA 90:823-825, 1928

6. Danielpour M, von Koch CS, Ojemann SG, Peacock WJ: Disconnective hemispherectomy. Pediatr Neurosurg 35:169-172, 2001

7. De Ribaupierre S, Delalande O: Hemispherotomy and other disconnective techniques. Neurosurg Focus 25(3):E14, 2008

8. Delalande O, Bulteau C, Dellatolas G, Fohlen M, Jalin C, Buret $\mathrm{V}$, et al: Vertical parasagittal hemispherotomy: surgical procedures and clinical long-term outcomes in a population of 83 children. Neurosurgery 60 (2 Suppl 1):ONS19-ONS32, 2007

9. Devlin AM, Cross JH, Harkness W, Chong WK, Harding B, Vargha-Khadem F, et al: Clinical outcomes of hemispherectomy for epilepsy in childhood and adolescence. Brain 126:556566,2003

10. Di Rocco C, Fountas KN, Massimi L: Anatomical hemispherectomy, in Çataltepe O, Jallo GI (eds): Pediatric Epilepsy Surgery: Preoperative Assessment and Surgical Treatment. New York: Thieme, 2010, pp 215-224

11. Gardner WJ: Removal of the right cerebral hemisphere for infiltrating glioma. JAMA 101:823-826, 1933

12. Hendrick EB, Hoffman HJ, Hudson AR: Hemispherectomy in children. Clin Neurosurg 16:315-327, 1969

13. Horsley V: British Medical Association. BMJ 2:670-677, 1886

14. Iida K, Otsubo H, Matsumoto Y, Ochi A, Oishi M, Holowka $\mathrm{S}$, et al: Characterizing magnetic spike sources by using magnetoencephalography-guided neuronavigation in epilepsy surgery in pediatric patients. J Neurosurg 102 (2 Suppl): 187-196, 2005

15. Kanev PM, Foley CM, Miles D: Ultrasound-tailored functional hemispherectomy for surgical control of seizures in children. $\mathbf{J}$ Neurosurg 86:762-767, 1997

16. Kestle J, Connolly M, Cochrane D: Pediatric peri-insular hemispherotomy. Pediatr Neurosurg 32:44-47, 2000

17. Krynauw RA: Infantile hemiplegia treated by removing one cerebral hemisphere. J Neurol Neurosurg Psychiatry 13: 243-267, 1950

18. Kwan A, Ng WH, Otsubo H, Ochi A, Snead OC III, Tamber MS, et al: Hemispherectomy for the control of intractable epilepsy in childhood: comparison of 2 surgical techniques in a single institution. Neurosurgery 67 (2 Suppl Operative): 429-436, 2010

19. Ojemann JG: Hemicorticectomy, in Miller JW, Silbergeld DL (eds): Epilepsy Surgery: Principles and Controversies. New York: Taylor \& Francis, 2005, pp 595-596

20. Oppenheimer DR, Griffith HB: Persistent intracranial bleeding as a complication of hemispherectomy. J Neurol Neurosurg Psychiatry 29:229-240, 1966

21. Peacock WJ, Wehby-Grant MC, Shields WD, Shewmon DA, Chugani HT, Sankar R, et al: Hemispherectomy for intractable seizures in children: a report of 58 cases. Childs Nerv Syst 12:376-384, 1996

22. RamachandranNair R, Otsubo H, Shroff MM, Ochi A, Weiss SK, Rutka JT, et al: MEG predicts outcome following surgery for intractable epilepsy in children with normal or nonfocal MRI findings. Epilepsia 48:149-157, 2007

23. Saneto RP, Wyllie E: Surgically treatable epilepsy syndromes in infancy and childhood, in Miller JW, Silbergeld DL (eds): Epilepsy Surgery: Principles and Controversies. New York: Taylor \& Francis, 2005, pp 121-142

24. Schramm J, Behrens E, Entzian W: Hemispherical deafferentation: an alternative to functional hemispherectomy. Neurosurgery 36:509-516, 1995

25. Shimizu H, Maehara T: Modification of peri-insular hemi- 


\section{Hemispherectomy}

spherotomy and surgical results. Neurosurgery 47:367-373, 2000

26. Torres CV, Fallah A, Ibrahim GM, Cheshier S, Otsubo H, Ochi A, et al: The role of magnetoencephalography in children undergoing hemispherectomy. Clinical article. J Neurosurg Pediatr 8:575-583, 2011

27. Villemure JG: Anatomical to functional hemispherectomy from Krynauw to Rasmussen. Epilepsy Res Suppl 5:209-215, 1992

28. Villemure JG, Daniel RT: Peri-insular hemispherotomy in paediatric epilepsy. Childs Nerv Syst 22:967-981, 2006

29. Villemure JG, Mascott CR: Peri-insular hemispherotomy: surgical principles and anatomy. Neurosurgery 37:975-981, 1995

30. Wetjen NM, Kestle JRW: Peri-insular hemispherotomy, in Çataltepe O, Jallo GI (eds): Pediatric Epilepsy Surgery: Preoperative Assessment and Surgical Treatment. New York: Thieme, 2010, pp 251-260
31. Widjaja E, Geibprasert S, Otsubo H, Snead OC III, Mahmoodabadi SZ: Diffusion tensor imaging assessment of the epileptogenic zone in children with localization-related epilepsy. AJNR Am J Neuroradiol 32:1789-1794, 2011

Manuscript submitted January 30, 2013.

Accepted March 11, 2013.

Please include this information when citing this paper: DOI: 10.3171/2013.3.FOCUS1341.

Address correspondence to: Alexandra D. Beier, D.O., Division of Pediatric Neurological Surgery, Lucy Gooding Pediatric Neurological Surgery Center, Wolfson Children's Hospital, 836 Prudential Drive, Suite 1205, Jacksonville, Florida 32207. email: alexandra. beier@jax.ufl.edu. 